Australia, New Zealand:

Mr F.E. Cook, Ionospheric Prediction Service, Commonwealth Center, Elizabeth Street, Sydney, N.S.W., Australia.

It is not necessary for observatories to receive all the "astrograms"; instead, subscribers can specify only the desired standard categories (the identifying telegram code word appears in the second column):

A. ALPHA Comet discoveries, brighter than magnitude 12.

B. BETA Comet discoveries, fainter than magnitude 12.

C. CHARLY Comet observations and brief finding ephemerides (primarily for observers).

D. DELTA Precise positions, orbits and ephemerides (primarily for computers).

E. ECHO Novae or supernovae, brighter than magnitude 12.

F. FRANCE Novae or supernovae, fainter than magnitude 12.

G. GAMMA All others, including planetary or lunar phenomena, spectroscopic binaries, etc.

Almost all the messages are transmitted according to a telegraphic cipher code. The code is described in Trans. IAU, XIIC, pp. 34-38, to which the corrections in Trans. IAU, XIIIA, pp. Ixxxiilxxxiii should be noted. Corrected reprints of the code may be obtained from the Central Bureau. Some messages cannot be cast in the standard coded form, but observers are nevertheless urged to include sufficient redundancy to prevent errors.

In addition to the astrograms, the Central Bureau maintains an even wider coverage by means of its postcard Circulars, which are issued irregularly about 50 times a year. These contain confirmations of the telegrams, predicted ephemerides for comets and unusual asteroids as well as observed positions, observations of novae and supernovae, and other astronomical information that requires rapid dissemination. About 600 observatories and amateurs subscribe to the Circulars.

The Circulars are available by advance subscription only, for 50 or 100 issues (not corresponding to a calendar year). These financial arrangements are entirely separate from the telegrams. The subscription rates below are those as of 1 December 1967 and depend on the destination and mode of transport:

$\begin{array}{lcr}100 \text { consecutive issues, airmail } & \text { North America } & \text { Other } \\ 100 \text { consecutive issues, surface mail } & \$ 15.50 & \$ 24.50 \\ 50 \text { consecutive issues, airmail } & 13.50 & 18.50 \\ 50 \text { consecutive issues, surface mail } & 9.00 & 13.50 \\ & 8.00 & 10.50\end{array}$

There will be a reduction of $\$ 1.00$ for subscribers who do not require invoices. Checks, bank drafts or money orders should be made payable to the "Central Bureau for Astronomical Telegrams".

\title{
V. THE PUBLICATIONS OF THE INTERNATIONAL ASTRONOMICAL UNION
}

A. TRANSACTIONS OF THE IAU

XIIIA_Prague 1967; pp. 1151, Reidel Publishing Company, Dordrecht, 1968

XIIIB-Prague 1967; pp. 319, Reidel Publishing Company, Dordrecht, 1968

B. PROCEEDINGS OF SYMPOSIA

24. Spectral Classification and Multicolour Photometry; ed. by K. Lodén, U. Sinnerstad; pp. 383; Academic Press (London), 1966; 120s.

25. The Theory of Orbits in the Solar System and in Stellar Systems; ed. by G. Contopoulos; pp. 380; Academic Press (London), 1966; 120s.

26. Abundance Determinations in Stellar Spectra; ed. by H. Hubenet; Academic Press (London), $1966 ;$ pp. $374 ; 120$ s.

27. The Construction of Large Telescopes; ed. by D.L. Crawford; pp. 234; Academic Press (London), 1966; 70s. 
28. Fifth Symposium on Cosmical Gas Dynamics: Aerodynamic Phenomena in Stellar Atmospheres; ed. by R. N. Thomas; pp. 483; Academic Press (London), 1967; 140s.

29. Instability Phenomena in Galaxies; ed. by M. Arakeljan (in Russian). Orders to the Meždunarodnaja Kniga, Moskva, USSR, or agencies.

30. Determination of Radial Velocities and their Applications; ed. by A. H. Batten and J. F. Heard; pp. 262; Academic Press (London), 1967; 84s.

31. Radio Astronomy and the Galactic System; ed. by H. van Woerden; pp. 501; Academic Press (London), 1967; 140s.

32. Continental Drift, Secular Motion of the Pole, and Rotation of the Earth

33. Physics and Dynamics of Meteors

34. Planetary Nebulae

35. The Structure and Development of Solar Active Regions

Proceedings of Symposia Nos. 24 through 28,30 and 31 are distributed by Academic Press, Inc. (London) Limited, Berkeley Square House, Berkeley Square, London W.1. In the Western Hemisphere by Academic Press, Inc., 111 Fifth Avenue, New York, 10003, N.Y. Orders should be sent to this address.

Proceedings of Symposia from No. 32 onwards are published and distributed by D. Reidel Publishing Company, Dordrecht, The Netherlands. Orders should be sent to this address.

\section{OTHER PUBLICATIONS PUBLISHED AND SPONSORED BY THE IAU}

1. Circulars of Commissions of the IAU. In addition to Commissions 26, 27, and 42 (see IAU Transactions XIIC, p. 44), Commission 41 (History of Astronomy) publishes the current bibliography on the history of Astronomy (editor P. G. Kulikovskij) and Information Circular. In 1964 1967, Nos. 7-14 appeared, edited by E. Rybka.

28. Proceedings of $1 A U$ Colloquia

(a) Blanketing Effect, edited by K.H. Böhm, Journal of Quantitative Spectroscopy and Radiative Transfer, vol. 6, no. 5, 1966

(b) Late-type-Stars, edited by Margherita Hack, Osservatorio Astronomico di Trieste, 1966

(c) The Fine Structure of the Solar Atmosphere, edited by K.O. Kiepenheuer, Forschungsberichte 12, Deutsche Forschungsgemeinschaft, Franz Steiner Verlag, Wiesbaden 1966.

(d) Evolution of Double Stars, edited by J. Dommanget, Observatoire Royal de Belgique, Communications, Série B, no. 17, 1967.

(e) Les nouvelles méthodes de la dynamique stellaire, edited by F. Nahon and M. Hénon, Editions du Centre National de la Recherche Scientifique, Paris, 1967.

(f) International Conference on Spectroscopy, 1967. Mimeographed proceedings in two volumes. Requests for copies should be addressed to: Scientific Information Officer, Bhabha Atomic Research Centre, Modular Laboratories, Trombay, Bombay-74, India.

\section{THE SYMPOSIA OF THE INTERNATIONAL ASTRONOMICAL UNION}

\section{Table 1}
No.
Title

\author{
Date and place
}
Editor and Publishing House

29. Instability Phenomena in Galaxies

30. Determination of Radial Velocities and their Applications

May, 1966
Bjurakan, USSR
June, 1966
Toronto,
Canada

May, 1966 June, 1966 Toronto, M. Arakeljan, Meždunarodnaja kniga (in Russian) A. H. Batten and J.F. Heard IAU-Academic Press
Organized in co-operation with 